MA PROJECT PAPER

STILL BIRTH: SOUNDWALKING GARRISON CREEK:

Ginger Raymond

August 24 $4^{\text {th }}, 2004$

\title{
CONTENTS:
}

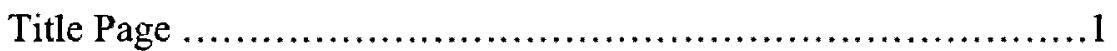

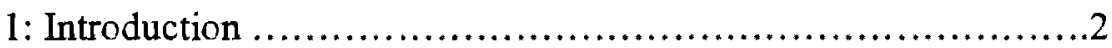

2: Acoustic Ecology ..........................................6

3: Westerkamp, Schafer, and Nature ........................... 12

4: Acoustic Anthropology and Listening ..........................15

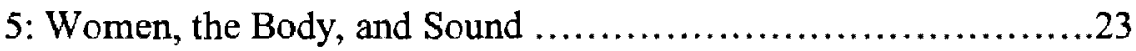

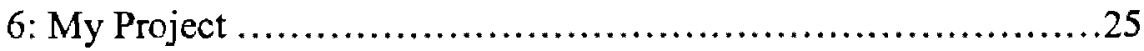

7: Commentary on 'The Soundwalk Soundscape' and 'The Mat' ......32

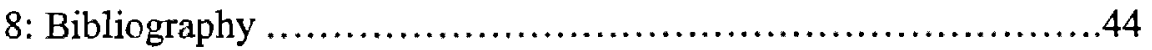




\section{1: INTRODUCTION:}

My project is about nature in the body and in the individuated imaginary, nature in the soundscape, sound in nature and the nature of sound. When contrasted to culture, I use Astuti's definition of nature as that aspect over which humans have no control $(1998,2001)$. My audio-piece is about how we locate ourselves through activation an activation very literal in soundwalking, which is mobile and receptive, and the creation of an accompanying soundscape which is a statement of personal engagement and, I hope, a communication event.

This paper will explicate my motivations, introducing the theory which has inspired my work. I include, in my final sections, a more personalised account of the development of my project. The project itself consists of an audio composition (a soundwalk and audio-book) and an accompanying embroidered mat, depicting the acoustic events of the composition.

I am so pleased to be able to present, in an academic forum, an experiment in parallel text, which I have come passionately to believe is quintessential to so much work in the social sciences. My project and paper enable me to climb around ideas, knock on their surfaces, and discover how a subjective resonance manifests...

If space is to be conceptualised as created and creative, the connotations therein are also premised upon a fear of actual and theoretical globalisation. This theme of individuation versus homogenisation will resurface throughout my work, and is 
verbalised though a reference to Clark's work on the Naked (the body in nature) as opposed to the Nude (the artistically transformed representation thereof) (1956:3). For my purposes, the naked connotes a form of embodied universalisms. We are terrifyingly identical biologically: the nude is a particularised (rather than eroticised) version of this nakedness, it is the location of the self amongst all humans, and the location of the human within nature. Explorations of sound resonate with the conceptual muddle of corporeal boundaries: Without meaning to cloak an excuse, therefore, I present my work as leaky at its core: Permeability as a conceptual theme is one which allows for an organic bountifulness, a decadence of exploration... it is messy, but I have references!

This arbitrary use of 'nature' is heartfelt. While I understand the value of recognising 'nature' as a construct, I truly believe it to be enormously powerful and useful to conceive of nature as an actual as well as metaphorical force, a concrete and mysterious aspect of our existence, but also a structural oppositional force in individuated, that is, personalised, creativity. My section on Acoustic Ecology and soundscaping will explain the ways in which this discipline has mobilized the concept of nature, partially as a nationalist statement. It will also champion the idea of exploring place in non-textually reductionist and non-visually determinist modes. The collapsing of experiential knowledge into an all-perceiving enlightenment subject is a scorching fear for any social scientist, and has implications which leak into all aspects of method and presentation'.

\footnotetext{
${ }^{1}$ Gell comically laments the middle-class British desire for visual/ spatial gestalt (1995: 236), with which 1, too, am surely afflicted!
} 
My third section will explain why I have found the soundscaping discourse on nature somewhat problematic: the fact that soundscapes (as acoustic products) are essentially aesthetic explorations translates as a focus on the creative rather than environmentally activist or nationalist cultural agenda of Acoustic Ecology, although the two are often presented as coterminous (especially in the work of Westerkamp, to whom I will principally refer).

My fourth section concerns the enormous advantage of 'sound' as an exploration of all the preceding issues: sound as a spatial phenomena places us, surrounds us, vibrates and permeates our bodies without permission: it is created with volition, it mobilises the space around us and resonates in its objects. This section will return to the naked/ nude, universal/ particular aspect of 'sound', and rely upon anthropological resources which offer an open-minded, but contextualised engagement which cannot be romanticised. I then go on to explore the feminised aspects of acoustic ecology and soundscape creation.

While I am using the feminine as a heuristic device, the proceeding sections will require that my concern with gender become more shapely and dense. It will introduce my own project concerns, those of exploring the mobile body within an actual space (in a soundwalk), and a sensory derive (Debord [1958] 1981). Personalised fears of unwanted pregnancy, and, simultaneously, infertility are invoked through the themes implied in the story of Little Red Ridding Cap; the budding fertility of Little Red Cap, and the stones she places in the belly of the wolf; her 
rebirth through the hunter's caesarean section on the wolf: ${ }^{2}$. This formal essay

explains why soundwalking provides an excellent means for exploring these themes, and why I feel my piece must contain a cohered, oral narrative.

\footnotetext{
${ }^{2}$ While I can present no evidence to support this state of mind as anything other than idiosyncratic (and thus potentially entirely esoteric, or worse, dull), I will add as a (leaky) aside that most young women I speak with will admit to profoundly sharing these fears.
} 


\section{2: ACOUSTIC ECOLOGY}

Whilst almost any social scientific project now must acknowledge the all-pervasive and ambiguous discourse of 'globalisation', I will not laboriously recount the various permutations of 'the local' and 'the global' (Wilk 1995; Tsing 2000; Savigliano 1995; Keamey 1995; Comaroff and Comaroff 1992; Abu-Lughod 1989): I will, however, note the distinct lack of attention to aurality in anthropology, psychogeography, and urban studies, illustrating the importance and originality of acoustic ecological approaches ${ }^{3}$.

Apart from escaping the perceptually dictatorial, and inherently imperialist objectification of 'landscape' in much painting and photography, or its textual reduction within much writing, sound and soundscaping allow me to nibble at a most enticing idea from Dewey: My product arguably aesthetic, and Dewey states that the work of art is, rather than the art product, the object working - an interaction which emerges from a bodily engagement which energises space (cited in Berleant 1985: 117). This same point can be convincingly made about soundwalking as a compositional method: as Westerkamp writes: 'I hardly ever use anyone else's recordings, because I am not interested in recordings per se, but in the experience while recording.' (2004b). Phenomenological concepts of landscape as experienced

\footnotetext{
${ }^{3}$ Much of the globalisation literature I have encountered is driven by concepts of rapid or fluid movement: 'flows' and 'scapes' (Appadurai 1991, Hannerez 1989, Kearney 1995, Gille and O'Rianin 2002, Inda and Rosaldo 2002). The investigative subject is encouraged to be hyper-mobile also, especially in terms of the multi-cited ethnographic practices espoused by Marcus (1995 Marcus and Fischer 1986, Eade 1997). Sound lends itself to this mobility - the difficultly in conceptualising of centres, peripheries, and various bounded and unbounded notions of place and experience. Schafer (1985) notes McLuhan's ideas of the electric (globalised) world as aural rather than visual, a theme not pursued by many scholars of McLuhan (see McLuhan 1967, 1964).
} 
through a sensorially engaged body, indicate that attention to the aural aspect of ones engagement with space (and with the representation thereof) merits weighty consideration.

Acoustic Ecology undertakes such explorations. The World Soundscapes Project was founded by composer R. Murray Schafer at Simon Fraser University in the 1970s. Other members were Hildegard Westerkamp, Barry Truax, Peter Huse, Bruce Davis, and Howard Broomfield. It addressed a number of issues: Psychoacoutsics, Education, Environmental studies (Bronzaft 2000), Urban planning, and Medical research (Schafer 1977a, 1977b, 1977c). The privileging of sound as a means to address and explore these ideas requires an acoustic language and a set of reproducible acoustic practices. In the case of language, it is continuously fascinating to note the humble clumsiness of much acoustic ecological literature, which continuously grapples with the expression of sound in text. The most elegant writers I have encountered have shone only in fitful descriptive flourishes. Certainly Schafer's musical background gives him a technically accurate and luxuriously metaphorical vocabulary.

However, in the case of both Schafer and Westerkamp (whose work I shall introduce shortly), our understanding must also be invigorated by an engagement with their acoustic works, reiterating my introductory point about the paramount importance of parallel texts. The criteria for a soundscape composition are stated by Westerkamp (2004b): Most important is the representation, within the recording, of the recordists' engagement with a specific place. My project is a soundscape composition, but includes narrative. It is composed by means of soundwalking, wherein one chooses an 
area and walks it with technologically amplified hearing. This enriches an

understanding of that experience and that place through sound: I include

Westerkamp's instructions as a foomote ${ }^{4}$, the essential features being orientation, dialogue and composition.

\footnotetext{
* Very little has been written about soundwalking in academic fields, exceptions being Norman 1996, Traux 1996 and McCartney 2004. Westerkamp gives us guidelines for a soundwalk: They seem to me to be in an action-research vein, sociologically motivated, and predicated upon allowing the research to tell its own story (Carter 1993, Coles 1989): "Go out and listen. Choose an acoustic environment which in your opinion sets a good base for your environmental compositions... What kinds of rhythms does it contain, what kinds of pitches, how may continuous sounds, how many and what kind of discrete sounds, etc. Which sounds can you produce that add to the quality of the environmental music? Create a dialogue and thereby lift the environmental sounds out of their context into the context of your composition, and in turn make your sounds a natural part of the music around you. Is this possible?
}

Start by listening to the sounds of your body while moving. They are closest to you and establish the fullest dialogue between you and the environment. If you can hear even the quietist of these sounds you are moving through an environment which is scaled on human proportions. In other words, with your voice or your footsteps for instance, your are 'tal king' to your environment which then in turn response by giving your sounds a specific acoustic quality,

Try to move

Without making any sound,

Is it possible?

Which is

The quietest sound of your body?

(If, however, the sounds you yourself produce are lost in the ambient noise of your surroundings you experience a soundscape which is out of balance. Human proportions have been disregarded here. Not only is your body inaudible but your ear is also assaulted by a multitude of loud and chaotic noises.)

Lead your ears away from your won sounds and listen to the sounds nearby.

What do you hear? (Make a list)

What e]se do you hear?

Other people

Nature sounds

Mechanical sounds

How many

Contunuoussoundscontinuoussoundscontinuoussoundscontinuoussoundscontinuoussounds

Can you detect

Interesting rhythms

Regular beats

The highest

The lowest pitch.

Do you ear any

I.t.e.r.m.i.t.a.n.to.r.d.i.s.c.r.e.t.e.s.o.u,n.d.s

Rustles

Bangs 
For the purposes of this paper, I will continue to explore the theory within the texts accompanying soundscape compositions: Schafer defines soundscape as 'a word I invented, it describes all the sound events of which a landscape, a place, a space is composed - the entire acoustic environment of our daily lives, wherever we may be, at home, at work, indoors, outdoors.' (cited in Dietz 2000:20).

Complex, natural soundscapes are 'hi-fi', wherein 'sounds overlap less frequently; there is more perspective -foreground and background' (1977a 43). Industrialised ones are 'lo-fi'. In hi-fi soundscapes, repeated and cyclical sounds are woven into intricate, un-masked, natural harmonics, as evinced in Krause's 'niche hypothesis' (1993). In low-fi soundscapes, the 'keynote' is often traffic, and the ecological balance is destroyed.

This is where concepts of globalisation and homogenisation appear - in the submerging of inherently particularised, localised soundscapes: The consequence of

Swishes

Thuds

What are the sources of the different sounds?

What else do you hear?

Lead your ears away from these sounds and listen

beyond...into the distance

What is the quietest sound?

What else do you hear?

What else?

What else?

what else?

I hear the soundcape as a language with which places and societies express themselves. In the face of rampant noise pollution, I want to be understanding and caring for this 'language' and how it is "spoken." (2004a) 
such devastation impoverishes all its inhabitants. Schafer was initially motivated to begin his acoustic ecological work because of the dramatic erosion of children's ability to listen'. The lack of 'acoustic colouration' in urban environments (i.e. the masking or obstruction of nuanced sound reverberations within that environment) means the loss of fundamental clues and signals about placement within that environment: as one is impaired, for instance, from recognizing one's own soundgenerations (such as footsteps): 'one's aural space is reduced to less than human proportions.' (Truax 1984: 20). Westerkamp draws an explicit analogy between her own voice and that which she feels is being silenced in nature: 'As long as we accept noise or the voices/ sounds of authority as the dominant sounds that set the 'tone' of an environment, other tones and voices (such as our own) have no place and are indeed often silenced.' (Westerkamp 1988:1)

The 'acoustic horizon' of urban centres is limited, and anti-informational noise proliferates, creating a continuous 'Sound Wall' or forcing individuals to take recourse to 'acoustic perfume' (Wrightson 2000: 12) such as music or broadcast speech. One need only to look at the sinister allure of i-pod advertising to recognise the exultant isolation of the undulating, silhouetted and thus isolated listener. Broadcast sounds create a 'schizophonic' situation, where sound is mobilized as defensive or aggressive. The resultant 'sound imperialism' is exercised by whomever in the environment is able to command 'sacred sound' i.e. sound which is exclusively produced by a dominating force, be it sacred/ religious or secular/governmental: The unfixed boundaries of sound are textual-spatial challenges, but also represent serious difficulties in legislation about sound.

\footnotetext{
${ }^{5}$ Soundscape composition and soundwalking, are one of a number of educational "ear-cleaning" activities which may be undertaken to achieve acoustic ecological goals (Schafer 1992, 1967).
} 
It is in specific, subjective placement of the self (attention to particularised place), that our more abstracted but also individuated imaginaries can be liberated. Kolber writes of Westerkamp's 'Kit's Beach Soundwalk' that the soundscape recording, references to concrete times of day, along with her visual descriptions, "provide the listener with a space to daydream, to take a moment to be.' (2002: 42). However, in this same article, Kolber identifies what seems to be a contradiction in soundscaping; While we are listening to the soundscape, we privilege certain voices within it: those small sounds of nature, schizophonically masked in lo-fi soundscapes; the imperative therefore is placement and imaginary displacement, not only within the realm of mythos, but within a denial of the lo-fi: 'to get rid of the city...pretend its not there.' (cited in Kolber 2002: 42). I note on the quandary of listening as meditation, and listening as social engagement, in my fourth section.

The slippage in composition, the space in which subjectivity is injected, a nudity as opposed to the nakedness of listening, is a marvellous and exhilarating process. However, while I believe in the ecological imperatives of soundscaping projects, I find it continuously problematic to actualise and mobilise, in my own work, a harmonious relationship to the 'natural' as an actual chthonian realm wherein I will be safely, even warmly, invited to explore myself, mythos, and the thunderous tidal roar of my embodied natural dictates. In my final sections and project, this will become clearer. Let me now move on to discussing how Westerkamp characterises nature as our friend, and not only a worthy ecological supplicant, but a benefactor in radical humanist consciousness liberation. 


\section{3: WESTERKAMP, SCHAFER, AND NATURE}

As I have implied, it is common practice in soundscaping that natural sounds (as contextulised) are amplified and championed. It is these small sounds - hidden in the rivulets beneath rocks, the wisps of wind on leaves, crickets and the inner-echo of cacti - that represent the neglected, particularised occurrences in our rich, inherently differentiated, soundscapes. The use of technological equipment is essential to the exploration of these sounds, and Westerkamp does so as a self-titled 'ecologist of sound.' (1998: 7).

'Westerkamp's stories are 'feeling dreams' accessible to a listener. By allowing him or her to discover meaning and order within nature, Westerkamp's stories have the potential to diminish a listener's fears of the unknown, of the roaring city.' (Kolber 2002: 42-3). This movement, away from the city, an escape into nature, and a return to urbanity's seemingly destructive presence renewed and armed, sits ill with my own understanding of nature and the city, a concern I elaborate in my sixth section. For now, I will state that while Westerkamp describes the function of soundwalking as orientation, I stress its functions of simultaneous disorientation, of sensory and imaginative derive (Debord [1958] 1981, see section on listening). It seems to me that, especially in artistic creation, nature is the loci of creative work, of a wrestling out of self from the chthonian. It is an awe-struck acknowledgement of the spiritual force of nature, but from this the creation of something resembling (at least at times) an integral self - a socialised participant within culture: the city can be a metaphorical representation of the latter part of this process. It is somewhere we situate ourselves, 
and it is in the mediation of these two states that we are able to create, in an acknowledgement of the profundity of our mortality, our biology, our body (as nature), and the variouness of its placement in culture. Using an audio-narrative in my piece, a familiar folk-tale, I speak to the transformational processes herein, as discussed in my final two sections.

Westerkamp's imperative is to 'care' for the voices of nature, and she speaks with compelling beauty and clarity in interviews, liner notes, and in the unpublished paper 'Listening to the Zone of Silence' of her experiences, her tactile adventures in sound, and the almost maternal responsibility she feels for natural sound producers. As evinced particularly well in her piece 'Cricket Voice' (1987), making nature our friend also employs a salvage mode which is associated (usually critically) with ethnography (I will identify more analogies between the approaches of soundscape composition and anthropology shortly). My understanding of nature as speaking though us, and certainly of its mistreatment in industrialised societies, is fundamentally in agreement with Westerkamp's ideas.

The mobilization of the concept of 'nature' in acoustic ecology is not only as a metaphor for well-being, both ecologically and psychologically, but also, as I have mentioned, as particularising. Beyond subjective personal experience, I would argue that the World Soundscape's Project wields nature in an inherently Canadian way, creating an 'imagined community' (Anderson 1991), especially in opposition to the United States. Westerkamp and Schafer, and other soundscape composers, are in many ways creating a nature which is identified within a conscientious ecological mode which might claim similar nationalism. 
Waterman (1998) writes that 'Schafer's environmental music is integrally linked to his concept of 'authentic' Canadian culture defined by geography and climate, the... 'Idea of North'. Schafer's 'Music in the Cold' (1977d), a poetic story-telling, wherein Canada takes over the world (essentially becomes the United states) and is reclaimed by an ice-age, does mobilise the harshness of Canadian nature, but along with Westerkamp he is interested in creating an engagement with nature which makes it a defining national feature, as opposed to places with less uncultivated space. Rather than a masculine ruggedness, acoustic ecology engages with the feminised mode of knowing identified by McCartney (2004), which I discuss in my fifth section. I will end this section by stating that while the mobilization of a concept such as nature in identity formation is akin to notions of classification in culture. Certainly, it problematises the category of nature (though potential reification), but I do feel my piece is significantly influenced my novel proximity to even the notion of the tremendous natural spaces in Canada ${ }^{6}$.

\footnotetext{
${ }^{6}$ In a recourse to visual imagery, Schafer writes that "the average Canadian carries around with him in his head a vision of spaciousness' (cited in Adams 1983: 59)
} 


\section{4: ACOUSTIC ANTHRPOLGY AND LISTENING:}

This section will address 'sound' and 'listening' in relation to place, and also more abstractly. Ecologically, the retention of context and attachment to place in soundscape composition (through limited electroacoustic distortion), in part serves the purpose of a socio-political engagement, acknowledging ones reasonability within soundscape. It also acknowledges a creative, grounded subjectivity, and offers a meditative commentary on the process of composition. This context distinguishes it from the 'sound objects' and 'found sounds' of Pierre Schaeffer and Edgar Verese. But as well as the ecological agenda of soundscaping, there is a meditative attention to mindfulness, a concept used by John Cage in his musical performance. I am inspired by Cage's play with boundaries when he writes: 'someone said 'Art should come from within; then it is profound.' But it seems to me that goes within.' (cited in Adams 1983: 41).

In soundwalking, I am receiving and creating sound and art, and placing myself therein: Cage explores chance music, making art and life continuous, and, like soundscapers, declares that environmental sound is music. The amplification of masked voices in the soundscape causes a shift in perspective and a reflexive form of listening which is 'a creative, enjoyable appraisal of the sound for its own acoustic properties.' (Norman 1996:5) ${ }^{7}$. Ear-cleaning, sensitive and meditative listening,

\footnotetext{
${ }^{7}$ It is by emphasising one particular sense that I think we are invited to 'derive' - a psychogeographic practice developed by Debord and the Situationists ([1958] 1981). A playful re-appropriation of space from authoritarian divisions and determined courses, the Situationists share with the soundscapers an interest in reclaiming place. However, while a derive requires that one 'drifts' in disorientation in order to better understand a place, soundscaping practices distinct, mindful listening, a directed course, and a concrete product: the analogy does retains utility since a derive aspires to present a new understanding
} 
enables one to "invent new codes, invent the message at the same time as the language. [It is] playing for ones own pleasure, which can create the conditions for new communication... the emergence of the free act, self-transcendence, pleasure in being instead of having.' (Westerkamp 1988:1)

Truax presents the soundscape as a mediator between the self and the environment. This representation seems incongruous with the slippage inherent in much other soundscaping literature where both the self and the soundscape are identified with nature. For Traux, our responsibility lies in mobilising that self which in turn creates a fertile personal experience of the soundscape and the environment (and nature). In this section, I will reiterate how sound and the experience of listening, can be devastatingly homogenising as well as nurturant to individuation. Such a notion requires that the self and the soundscape are fundamentally (and literally) permeable concepts. This will become clearer as I now turn to ethnographies of sound, often cited by soundscapers.

Ethnography and soundwalking share heuristic parallels: they are both participant observation activities, and both quintessentially rely on the researcher as the research instrument: both 'privilege...the body as a site of knowing. Ethnography is an embodied practice: it is an intensely sensuous way of knowing. The embodied ethnographer is the instrument.' (Conquergood 1999: 4).

of place, one elicited though deliberate disorientation: This reverses the central anthropological tenant from Malinowski that we should make the bizarre familiar (Strathern 1987), if only as an ultimately stabilizing deviation. We displace ourselves from where we think we are, in order to understand where we really are, or where we might be also or by preference. Engaging with and activating subjective placement aurally also offers this gymnastic exercise. Part of the reason I have chosen to soundwalk Garrison Creek is a playful nod to the Situationists, whose reclamation of joy in the city bears the slogan 'Beneath the pavement, the beach!.' 
A favourite ethnography amongst soundscapers is 'Sound and Sentiment' (1982), authored by the trail-blazing and very brilliant anthropologist Feld. Feld writes that his ethnography is academically situated within (what he himself terms) Acoustemology, exploring 'acoustic knowing as a centrepiece of Kaluli experience; how sounding and the sensual, bodily, experiencing of sound is a special kind of knowing, or put differently, how sonic sensibility is basic to experiential truth in the Bosai forests. Sounds emerge from and are perceptually centred in place, not to mention sung with, to, and about places. Just as 'life takes place' so does sound; thus more and more my experiential accounts of the Kaluli sound world have become acoustic studies of how senses make place and places make sense.' (Feld 1994: 2)

Amongst the Kaluli of Papua New Guinea, birds are identified by their songs, rather than as visible creatures: The voices of the birds represent the voices of the dead, of spirits, and it is in this culturally specific connotation of hearing reminds us that sound too is subject to construction. Gell writes that 'the Umeda word for "mountain (sis) should be understood precisely as 'the sound that a mountain makes', or more precisely 'the shape in articulatory acoustic space' made by a mountain' (1995: 232). He writes about the intimate effects of landscape and place on their aural/oral representations in human culture, explicitly linking an anthropology of the senses to an anthropology of landscape.

An 'anthropology of the senses' was concertedly undertaken beginning in about the 1980's (e.g. Seeger 1975, Ohnuki-Tierney 1981, Feld 1982,1986, Stoller 1984, Tyler 1984). It was mobilised against occularcentric ways of knowing, epitomised in 
Durer's etching of 'Man Drawing a Reclining Woman', The connotations thereof (all that the grid excludes) and of seeing as encompassing and dominating, oppose the fundamental anthropological precept of empathising with the native's point of view (Malinowski 1922). It embraces bodily modes of knowing (Howes 1991), stemming from the idea of cultures as possessing a 'contrasting ratio of senses' (Ong 1982, McLuhan and Carpener 1960). Importantly, for McLuhan the electric world is aural ${ }^{9}$, making the contemporary exploration of sound more ethnographically pertinent. Ethnography forms a brilliant counterpart to soundscaping both in the scrutinising of context (in understanding and representing a place), and the open-mindedness of subjective investigation. Landscape is not framed within a detached, visually determined object-relation, but is known by embodied participation. An anthropology of the senses provides tools and directions for soundscapers, who sculpt with a sense devalued in the West (Jay 1994, Synnott 1991).

Ethnography has, as part of its self-reflexive and highly self-critical practice, taken issue with conventional forms of knowing. The reduction of another culture to a text, the difficultly of interjecting the subjective without undermining what is premised as a social-scientific, and thus partially objective, research endeavour, has meant that parallel texts, be they experimental writings or films, are championed by many. In the face of post-modernism, and post-colonialism, many anthropologists have tried to move away from visualist metaphors that imply dominance, and a simplistic devouring of the Other: Fabien suggests that anthropologists: 'rethink ethnography as primarily about speaking and listening, instead of observing' (cited in Conquergood

\footnotetext{
${ }^{8}$ In terms of gridded separation, one finds a powerful analogy in the work of Schafer (and therefore in Acoustic Ecology), which utilises 'glass' as representative of a phantom-like silence, an acoustic double-glazing (Schafer 2004).

${ }^{9}$ McLuhan suggests that sound is all centre and no margin (Scahfer 1985: 113), a point relevant to acoustic ecological concerns with globalisation.
} 
1991: 183). Clifford, the pivotal figure in the 'experimental turn' and 'crisis of representation' within ethnography (Clifford and Marcus 1986, Clifford 1988) suggests that 'Once cultures are no longer prefigured visually - as objects, theatres, texts - it becomes possible to think of a cultural poetics that is an interplay of voices, of positioned utterances. In a discursive rather than a visual paradigm, the dominant metaphor for ethnography shifts away from the observing eye and towards expressive speech (and gesture). The writer's 'voice' pervades and situates the analysis, and objective, distancing rhetoric is renounced.' (Clifford 1986: 12).

However, acoustic representations are indeed neglected in anthropology. Ethnographic explorations of sound read very beautifully, but they, like acoustic ecologists, still struggle with translating contextual, subjective acoustic experience into text. They also struggle with expressing ethnography acoustically; Westerkamp's piece 'Gently Penetrating Beneath the Sounding Surfaces of Another Place' (1998), a soundscape composition about New Delhi in India, might approximate an acoustic ethnography, but her interests in dialogue are principally characterised as complicity probing sounds rather than people, and therein remains fundamentally different ${ }^{10}$.

Carpenter states that 'Any sensory experience is partly a skill and any skill can be cultivated.' (1972: 20). An encouraging message for acoustic ecologists, this statement also cautions me against romanticising sound: We learn to know (in this case hear/produce sound) culturally, a principle statement in all anthropology. So while we cannot lay claim to a pan-human mode of listening, I maintain that the experience of listening, and of producing sound, engages a pan-human biology in a

${ }^{10}$ Truax writes about soundscape composition as global music and the analogy of understanding the music from another tradition as requiring 'listening from inside and listening from outside' (2004, pages uncited) 
way that visual knowing does not. Certainly, the amplification and manipulation (of nature sounds) in the work of Westerkamp and others metaphorically attends to small, neglected voices in nature and in ourselves. Recognising this as a distortion (from our technologically un-enhanced soundscape) has led, personally, to discomforting technologically aided soundwalking, and caused a continuous oscillation between modes of 'being', mindfully, in a place, and of creating within that place.

Listening requires that we be aware of our inherent placement at the centre of our audio space, where concurrently we stand at the periphery of our visual space: Schafer, in his dazzling article on McLhuan's understanding of 'acoustic space' (1985) states that McLuhan's spatial metaphor of a 'sphere' of sound $(1964,1967)$, is a symptom of the 'sound walls' created by 'sacred sound-producers' as part of a 'territorial conquest' (Scahfer 1985: 109, Karlsson 2000, Franklin 2000). In fact, our variegated reception of sound is omni-directional, better supporting McLuhan's claim that acoustic space 'is a simultaneous field of relations... its centre is everywhere and its horizon nowhere.' (cited as manuscript in Schafer 1985: 106). However, I would suggest that there is something to be retained from McLuan's stance, since whatever the rich diversity and unpredictable directionality of sound, we find ourselves at its centre, a resonant receptacle and embodied producer, of sound. Indeed, Schafer writes 'Visual awareness is unidirectionally forward, auditory space in omnidirectionally centred.' (Scahfer 1985: 112).

A potentially power-wielding detachment in the visual (to see is to possess or dominate) is undermined by the experience of omnidirectional sounds, demanding the involvement of the body in its environment: ' $I$ do not see it according to its exterior 
envelope; I live it from the inside; I am immersed in it. After all, the world is all around me, not in front of me.' (Merleau-Ponty, cited in Berleant 1985:117). Bohme's 'ecological aesthetic of nature is that the human being, in relation to the environment, is primarily, not a rational but a corporeal being - we live in and with nature because air, water, and soil literally pass through out bodies' (cited in Karlsson: 2000: 13) Auditory engagement allows metaphorically and viscerally for the exploration of a 'lived space' (Bollnow cited in Berleant 1985: 118).

Place is lived through and by us, but we are not simplistically its origin nor its terminus: the penetration of sound within that body elides the boundaries of self and other ${ }^{11}$, but also needs to be processed through an individuated integrity, and the battle to maintain a self in this dissolve can take place very profoundly in the imaginary. This is a communication event, it cannot be reduced to an exchange, but is an act determined by context.

I propose that the explicit engagement with the boundaries of sound and of the body in my project, locate it as a bold attempt at communication: 'Sight isolates, sound incorporates' (Ong 1982:72): Much evidence from ethnographies of aural cultures (Howes 1991, Weiner 1991, Feld 1982) suggests that aural cultures are inherently more communal and more 'sympathetic', because of the immediacy and personalised nature of this dominant sensory mode; Ong states that 'The mystery of sound is not the only mystery among the senses...But the mystery of sound is the one which ...is the most productive of understanding and unity, the most personally human...' (cited in Beck 1993: 5) The acoustic ecological desire to foster socially responsible and

\footnotetext{
11 Truax writes that "...the sound arriving at the ear is the analogue of the current state of the physical environment, because as the sound travels it is charged by each interaction with the environment.' (1984: 15)
} 
supportive 'communities' is therefore well served in explorations of sound. That aural/oral cultures may be more sympathetic supports the points made earlier suggesting that sound can be a sensory equalizer. 


\section{5: WOMEN, THE BODY, AND SOUND:}

Gender symbolism is essential in many ways to this project. Femaleness as associated with nature (Ortner 1974) stands against projecting, phallic vision and connotatively sexual domination. Also, femaleness is associated with a receptivity I have presented as intrinsic to acoustic experience, and soundwalking. This permeability is also employed in the exploration of (Jungian) mythos and imaginary, and in poetic creativity (Labouvie-Vief 1994): There is a useful correlation between the initial breach of the (female) self, and then the contained swelling - the growth and transformation - of creative substance. Similarly, a more transient mediumship in receiving the poetry of place might be heuristically characterised as anatomically female (Lewis 1989, Boddy 1988). Rather than landscape being feminised by a projecting viewer, it is the persona of the landscape/ environmental dweller that is feminised: Landscape is thus lived and worked, and art as lived and worked:

Soundwalking activates these concepts.

McCartney suggests that soundwalking might be characterised as a particularly feminised social-scientific methodology ${ }^{12}$. The sympathetic engagement with place which sound invites was explored in the previous section. The feminisation of soundwalking can be seen as practical benefit, since it allows for a dialogue (Westerkamp 1974:25, McCartney 2004, 2000), a greater interest in inter-dependence

\footnotetext{
${ }^{12}$ A lesson from the anthropology of the senses is not to romanticise sound: Indeed, Seeger (1975:214) discusses the 'male voice' as equivalent to a 'male gaze' (Mulvey 1989), since 'plaza speech' is most valued and spoken only by men. In Westerkamp's voicing of acoustic ecological goals to make small voices heard amongst the din of oppressive, lo-fi environments we see a sounding equivalent to "looking back'. However, since I am concentrating on aural rather than oral forms of experience, I still find it very useful to characterise soundwalking as feminised.
} 
and complementarily rather than exclusionary dichotomies. The consequent emphasis upon letting places speak for themselves, and the idea of the 'artist as channel'13 (Oliveros 1984 in McCartney 2004: 123-7, Paglia 1990, Kristeva 1987) again identifies receptivity ${ }^{14}$. I would volunteer Horney's point that girls and women find it more difficult to see their genitalia, as a reason that femaleness may be associated with non-occularcenric ways of knowing, and 'the greater subjectivity of women as compared with the greater objectivity of men.' (cited in Paglia 1990:22). It is the vibrancy, the embodied tactility of this trangressive receptivity that I am attempting to mobilise both in the subject matter and in the practice of composing my project:

'Sound is inner structure and outer context' ${ }^{15}$ (McCartney 2004, pages unnumbered).

\footnotetext{
${ }^{13}$ However, the acoustic ecological venture in soundscaping requires that the composer be a 'channel', but also a kind of 'facilitator' for the neglected non-hostile voices of nature, a position I have identified as problematic.

${ }^{14}$ Wordsworth warns (or laments): 'We cannot bid the ear be still'. McLuhan and Carpenter write that 'We can shut out the visual field by simply closing our eyes, but we are always triggered to respond to sound.' (cited in Duffy: 1969:23)

${ }^{15}$ Poetic inspiration for this work principally comes from Dickinson, who mobilises this dualism in the absurd imagery of her poem: An ear can break a human heart/As quickly as a spear, / We wish the ear had not a heart/So dangerously near': the bizarre association of the ear with projecting missile and the receptacle thereof, affords an interesting meditation on the body. Memorising and incanting poetry on my soundwalks has been a form of armament and a form of forgoing, of complicit surrender.
} 


\section{6: MY PROJECT:}

Wrightson (2000) bemoans the reduction of Schafer's ideas to simplified, soundbitefriendly concerns with noise-pollution. My initial readings of Acoustic Ecological literature are scattered with angry notes on this very issue, not only because it makes the sounds of nature our friendly allies, but because it misses what for me is the exciting potentiality of soundscaping. Lorenz '...maintains that acoustic ecology, judging by its projects, and despite its interdisciplinarity, has been dominated by aesthetic-artistic rather than social scientific attitudes...' (Lorenz 2000 cited in Karlsson 2000). I find it impossible to take issue with the political aspirations of acoustic ecology; undeniably, an 'impoverished' soundscape, and I cannot romanticize its disempowering connotations for people living, say, beneath a constant barrage of aeroplane noise!

Scahfer's 'soundwalls' act 'audioanalgesically', blocking and distorting ones inner emotional and psychological states; as discussed in my previous section, connecting to the body is essential to connecting with any sense of self. But in order to create, to wrestle with mythos, and cultivate individuality in art, we must in some sense work with and against this body: Goldschmidt writes that it is the "disengagement from the strictures of biological imperatives that has given humankind its prominent position in the world and led to its globalisation...It was the ability to recognise the overwhelming validity of the imaginary forces that substantiate these various selfdestructive [i.e. non-Darwinian] forms of behaviour that makes the human species different from all other creatures. (1993: 356). 
In artistic expression, the reproduction of this destructiveness must be wedded to the revered but feared muse: nature. As Paglia writes 'In the beginning was nature. The background from which and against which our ideas of God were formed, nature remains the supreme moral problem.... Our physicality is torment, our body the tree of nature on which Blake sees us crucified' $(1990: 1,3)$ 'Nature is no respector of human identity...only in society can one be an individual' (Paglia: 1990: 4, 39).

It is this engagement with nature in soundscaping, the bluntness of the statement about placing oneself in accordance with nature in order to create, that most excites me about the genre. Whilst I am entirely seduced by the force of Paglia's statement that 'Everything great in Western culture as come from the quarrel with nature' (1990: 28), I must resubmit my fundamental agreement with the environmentalist imperatives of acoustic ecology: I do not think we need to drown out the sounds of nature. However, I do think that these sounds need to be awesomely respected without being domesticated as inherently friendly, in order that the nature of imaginative creation be personally meaningful.

Many nascent ideas for my soundscape composition are flecked with inspiration from the use of Numinous Objects amongst the llahita Arapesh of the East Sepik Province, Papua New Guinea, discussed by Tuzin (1984): The bullroarers used in rituals reproduce the sounds of thunder, eerily powerful because they are reminiscent of inaudible sonic frequencies, challenging the social-scientific analytical collapse of interpretation with experience: Tuzin writes that 'one's particular response to a piece of music depends not only on the culturally specific, outward form of the music, but 
also on primitive response mechanisms having to do with emotion, cognition, and the auditory apparatus.' (1984: 581). 'There is no doubt', writes Needham, 'that soundwaves have neural and organic effects on human beings, irrespective of the cultural formation of the latter.' (cited in Tuzin 1984: 581). In their ritual performances, the sounds produced by the bullroarers remain mysterious to the initiated men, who have become musicians and thus party to technical understanding.

What allures me in this ethnography is the space it allows for respect and reverence in the imitation of voices which are not our own. The distress at producing an entirely esoterically personalised project is something I wrestle with: Drever writes about the danger of 'sonic tourism' and 'sonic fetishism', cursory or irrational attention to organised, reproduced sounds (2002:21). I have tried not to make sound anecdotal, but personalised and grounded, thus allowing my creative experience (and product) to be viscerally and imaginatively communicable.

Because of my interest in the nakedness of sound, it seemed apt that the subject matter for my own composition be based upon universality and the body. The boundedness of the self as compromised though sound, the explicit metaphorical and actual importance of the body in soundscapes, brings me to the profound compromise of bodily boundaries in conception and birth, and thus my decision to use Red Riding Cap as my vocal component. As someone who has never been pregnant, I am unable to create with any convincing volition, a piece about birthing and motherhood ${ }^{16}$.

\footnotetext{
${ }^{16}$ Westerkamp has composed 'Moments of Laughter', a piece on motherhood which includes birthing sounds: it was a composition given little commentary within the electroacoustic community (McCartney 2004).
} 
However, as a woman, I can only honestly confess to the horrendously dictatorial imperative to procreate as an invited and uninvited force ${ }^{17}$.

I submit that my every creative action is predicated upon my understanding of what it means to biologically procreate: 'The more woman aims for personal identity and autonomy, the more she develops her imagination, the fiercer her struggle with nature - that I, with the intractable laws of her own body. And the more nature will punish her: do not dare to be free! For your body does not belong to you! (Paglia 1990: 10, de Beauvoir [1949] 1997). I feel that the most challenging way for me to take advantage of the project option in this programme is to create a piece using sound which directly and simplistically addresses these fears and this conflict: soundscaping, for the reasons outlined above, offers a way to revere and acknowledge the body and nature, but also to create with and against it. Imposed fictional narrative, chronologically and directionally ordered, is a statement of personality.

Artistic creation is, in itself, "a ritualistic binding of the perpetual motion machine that is nature." (Paglia 1990: 29) and "The most effective weapon against the flux of nature" (Paglia 1990: 28). I hope I have made clear that it has been necessary for me to adopt a feminine persona as Paglia suggests Dickinson did, donning a cloak of

\footnotetext{
${ }^{17}$ Just as receiving sound cannot be romanticised as a universalised experience, so birth is multifariously constructed across cultures: However, Bloch and Guggenheim (1981) have convincingly argued that cross-cultural similarities can be posited: The importance of acknowledging the natural reproductive abilities of (exclusively) women must be wedded to the instantaneous declaration that ideological, vastly varied creative (ideological) forces as necessary to transform the birth process, and the baby, into a clean, moral, socially integrated person. This reiteration of the work of Durkheim (1963) and Levi-Strauss (1963), exploring how oppositions within nature reflect those within culture and society, is thus reversed: we use nature to create, and then recreate nature in the image of those constructions. I am inspired by Douglas' work on sex, morality, experience, and boundaries (1966, 1975), in that it shows how we can use nature to think and culturally categorise.

Much work has been done on the cultural variability of birth (Leach 1966 on the 'Virgin Birth Debate', Carsten 1995, Greenlaugh 1994, Theissen 1999), but Bloch and Guggenheim discuss the near universal symbolic use of sexual dimorphism in the legitimating of the second, ritualised and socially integrating, birth: 'On the common humiliation of mothers are built the varied and many symbolic constructions of power.' (1981:385)
} 
femininity through the reference to Red Riding Cap's cloak, which is why her poetry

becomes so apt. Dickinson's sexual abstinence speaks the themes of receptivity, both

literal and metaphorical, required to listen, hear, and creatively compose $\mathrm{e}^{18}$.

The locomotion of the body though a place, and communicating with that place within

the process (as well as trying to communicate this to other people), is wedded to

romantic notions about paths (and to the story in Little Red Riding Cap): 'There has

always been something preternatural about paths... for not only poetry but folklore

\footnotetext{
${ }^{18}$ I deliberately read much of Dickinson's poetry because of Paglia's adulation of Dickinson's creative persona: It speaks to the receptivity I have mentioned throughout my essay, a receptivity which is inherently feminised in listening, in composition, and in the social scientific modality of acoustic ecology: This can be posed as a gendered dichotomy with notions of landscape as female and receptive, and the wilderness as a space to be cultivated by an aggressive male persona. Paglia states that women represent a distressing wholeness, a self-contained fullness, because of their diffused sexual experience, and their creative capacity which requires only sexual passivity, then nurturance to an active foetus/baby. I think this wholeness is compromised in listening, problematising definitions of femininity as does Dickinson: At the beginning of her chapter on Dickinson by stating that: 'Storytelling or yam-spinning is what men do among men. It is a ritual of avoidance, a deflection of the psychological turbulence of men's lives with women.' (1990: 623). Dickinson's graphically literal metaphors are a 'technique of self-hermaphrodization' a 'Brontean swerve from gender' (1990:640). As 'externalizations of internal events, they are an emptying out of female internality' (1990: 640). What mode could be more apt for a soundwalk? Our conversation with place requires that parts of us are admittedly permeable, for receptivity to novel sensory engagements with that place. Paglia quotes Aquinas: 'A body is composed of potentiality and act; and therefore it is both active and passive.' (1990: 647). Thinking about Dickinson, I have mediatated on my own poetic abilities and realised I cannot produce adequate verses of my own: Using the story of Little Red Cap, in its various (chronologically presented) adaptations, l attempt to mobilise Paglia's notion of Dickinson's persona. The potentiality also lies in the un-interpreted fairy story of my choosing, and the oft-walked route of my soundscape. It requires an adoration of nature but an acknowledgment that for the imaginary to become individuated, a characterisation of a benevolent nature and humanity must ultimately be abrogated. Paglia writes that, while women are (more) whole biologically, 'Culture... was invented by men, because it is by culture that they make themselves whole.' This division is entirely seductive to me as a scholar and the various other guises we all can claim. Dickinson's warding off of her own gender, speaks to my own concerns with infertility and unwanted pregnancy and their implications for academic and creative work such as this: Paglia writes that the choice not to have children is about 'imaginative integrity' - 'Art is its own self-swelling, proof that the mind is greater than the body' (1990: 660). Making art, we create objects from our imagination, from its flux: hearing, we select also, we are essentially human in our translation of sound, but essentially animal also. Sound too, is a kind of impregnation, filling, a movement. While I make no grand claims for this piece, I can easily extend the very literal fears from my body to the success of this creative piece. Whenever I speak to anyone working creatively, their personified work takes on an almost human quality, they talk of their art like babies, with angst, care, and compromise. In Dickinson the sentimental feminisation of her persona allows for a creative masculinisation, and a lesbian evocation of the Muse. Choosing the Red Riding Cap narrative, with its connections to the adolescent formation and self-conscious acknowledgment of femininity (a red cape donned, sexual allure realised, as she climbs into bed with the lascivious wolf) aims to do a similar thing with a genre which does not always acknowledge the violence of its muse and creative materials: nature. Nature is both masculinised and feminised, it is benevolent and destructive, in organic and bodily, and creative imaginary senses. Sound, too, requires passive and active modes, and the soundwalk both dictates to and is dictated to by my narrative.
} 
abound with symbolic stories about them: paths that divided and become two paths, paths that lead to a golden kingdom... paths that not merely divide but become the twenty-one oaths that lead back to Eden.' (Lowry 1969 in Berleant 1985: 123). Paglia writes that 'Walking in nature, we see, identify, name, recognize. This recognition is our aprotopion, that is, our warding off of fear'. (1990:5). In answer to this latter quote, I resubmit that characterising nature as our warm guide on a soundwalk is personally certainly antagonistic, but I do believe in the potent ability of soundwalking to subvert process of visual, categorical domination.

Martin writes that 'Our first intentional voice sound comes not as a statement of our needs, not as an attempt persuade those around us to act, not as a reaction to the birth trauma, but as an assurance of our very existence- tactile and auditory proof that we have arrived in a new environment and are now an entity all on our own' (2004: 261). I want my story soundscape piece to reflect the way I hear as well as the way things sound. Initially, experimenting with a variety of readers proved incompatible with this project, since they seemed to negate my personal accountability in the project (however simplistic that might seem), and also because aesthetically I appreciate one guiding voice when I listen, this is an invitation for ebb and flow (a give-and-take) within hearing.

As listeners, I have in mind people who are familiar with my soundscape. Also, people with whom I should like to communicate with about that soundscape, most especially my young sisters who live in British Columbia: At age nine, they also represent an excellent challenge in terms of making academic theory accessible! I want them to know about the soundscape but also about how I engage with it, how it 
places me personally, and how the need to communicate this is an essential aspect of that experience. The intimacy of this directedness affords a certain licence, and a certain humour, but also a greater potentiality for care and accountability within the project.

This parallel audience allows me to explore concerns about the portability of this audio product, and its reproducibility, the Benjaminian (2001) tactility of its (artistic) aura. Art as object-creation, and this product as a mobile audio-piece, is fundamentally opposite to the dynamism and cyclical soundcapes of nature. If places gather 'things', memories, and histories, I want to mobilise that holding in my reproduction of place, and in the textile presentational forum which forces people to create a new space: every listening experience is mapped as individual (I give a more detailed description of my textile mat after in the final commentary section). This actualises Ong's contention that 'Sound exists only when it is going out of existence. It is not simply perishable but essentially evanescent, and it is sensed as evanescent.' $(1982: 32)$.

While we cannot know nature necessarily, we can mobilise it creatively. Ong suggests that 'Words in the oral-aural culture are inseparable from action, for they are always sound.' (Ong cited in Stoller 1984: 561), whereas 'We take the language of sound for granted' (Stoller 1984: 569). Within this cultural bias, I am attempting to mobilise the dynamic and energizing phenomena of 'sound' and 'hearing' (Adams 1983: 316), to submit my created integrity, and its leaky adventures in communication. 


\section{7: COMMENTARY:}

\section{The Soundwalk soundscape}

The whole piece is about 46 minutes long, and is not (as I initially planned) structured by a harmonic looping, or series of repetitions. The almost un-altered real-time and mundane familiarity of the sounds in this piece are intended to invite the listener's imagination to drift. It is a gentle piece requiring only partial attention. The modest transformations that are present retain a reverence for the original context of the sounds and the distance of the listener. And while I cannot presume that listeners will have encountered similar soundscapes, certainly the various soundwalks I have conducted in other parks have gleaned results remarkably similar to the ones I present in my project. It is thus (potentially and hopefully!) a collaborative piece, contingent upon listener reception, implied by the multiple footsteps within the soundwalk. 0:00 Begins with first attempt at recording... my principle listening space for this composition has been wondering through Trinity Bellwood's park or sitting at my balcony (both on the Garrison Creek trail), so this is representative of that meditative space, a double-layering of the soundscape upon its original context in my listening practices...

The triptych of boiling sounds represents the three woven soundwalks of the subsequent minutes, the three transformed soundwalking experiences, and draws attention to the water and birdsong sounds emphasised throughout. These are the sounds which I have found most immediately charming and symbolically stimulating. 02:39: Introduction of pedal-miked footsteps, and my indulgent attention to the interior, enclosed, womblike sounds of this footsteps, rubbery and self-conscious. 
These disappear, and reappear at the end of the recording. The mat encourages one to become aware of ones own footsteps in a live audio and tactile sense, constituting an anti-Folly (I used a Folly mat to play with the generation of artificial walking sounds, such mats are used to create soundtracks for film or sound effects for audio work).

The footsteps in my recording introduce a notion of rhythm which is explored through various repetitions throughout the piece. Murch (1994) discusses how, in human developmental terms, hearing is the first of our senses to develop.

The path traced by the walk results from the narrative, the footsteps evocative of repetition and the soundwalks of ambience, surround, and weaving, swimming sounds, an indiscriminate propulsion in contrast to the directed, word-formed narrative. Schafer believed that 'the various senses are bound together by the biological and neural rhythms of the human anatomy. The real meeting place of all the arts is therefore rhythm." (cited in Adams: 1983 38). This returns us to Murch's comment cited above. At times, the aforementioned footsteps almost become heartbeats.

Simultaneously, I play with dropping into water some objects from the walk - sticks, stones, and glass. Dropping the stones in water and stirring them refers retrospectively to the boiling sounds, the cooking of my ideas...

Traffic is also introduced here, the most prominent sounds on my walk were traffic sounds, engulfing, watery, tidal sounds, abhorred in acoustic ecology but retaining a mesmerising, powerful allure and binding familiarity.

05:06: Introduction of narrative, loud and over-lapping, all versions of Red Riding Cap are introduced, and the sound-poetic reading of Ladle Rat Rotten Hut is fished 
out, played quietly, it is, as are all the readings, one-take reading, this one being an experiment in the sound of words, an outpouring of voice which is seemingly nonsensical, yet in parts identifiable with the other more lucidly recounted adaptations of Little Red Riding Cap.

The order of the stories (after Ladle Rat Rotten Hut) reflects the progression from oral tale to written narrative. The first nonsense reading is in fact written, but is a playful engagement with the sounds of words, a self-conscious looping to the final written version which we most often encounter.

Recording a narrative with my soundscape engages a 'detective' genre (wherein lie variously identified villains of the piece, for example), one fundamentally visual according to Ong (1982: 149). A fictionalised soundwalk narrative, is also a different form of vocalisation than Westerkamp's commentary in her soundwalks: a narrative is an imposition, as a popular folk tale there are allusions of thematic communicability, but it is still more aggressive than a passive commentary. It suggests a linearity in order to emphasise the circularity of nature, the give-and-take or the harmonic hi-fi acoustic balance, and as an assertion of creative process which carries the listener on a journey also.

06:02 The cascading sound of a roof being demolished is heard. This and many of the louder sounds within the recording are from my least-favourite soundwalk, their volume is emphasised because of the distressed difficulty I experienced whilst recording. 
The wind plays with my mike in the recording... a growling statement of mediation, of the aggression of nature on the compositional and recording process, of my amateur status and naivety as I am still learning the skills of this discipline. It also reminds me of nature as a hostile force. The various human voices on the soundwalk feature as prominently as any sound from 'nature', but are fleeting, they are not stilled by contentious meditation.

10: 19 This version of Little Red Cap is the oldest I have found, and has no hunter to rescue the heroine at the end of the story. The line of the story stating: 'The path of the needles, or the path of the pins' is a literal inspiration for the mat, also. In this recording, I read as if I were reading (in many respects I am reading) to my young sisters. This requires a self-consciously intimate translation of my compositional process and theoretical motivations, juxtaposed with the hauntingly lonely yet liberating anonymity of the traffic. Part of my longing for my sisters presence is also adulation of the way they listen, so easy and mobile, a mode absolutely ideal for this piece.

15:57 Here I am dropping stones in water on the walk, like I did in the studio with the found sounds. I used the same stones to test out their different qualities, more pronounced in the actual process of recording than in the product!

17:00 I introduce the Grimm version of Red Riding Hood, coming after the principally orally communicated version of Little Red Cap. My reading is juxtaposed with the construction noises from children who are building in a summer arts program. These noises speak to my earlier recordings of the roof being destroyed. 19:18 The water sounds from the water park (louder as they are taken from my least favourite walk). 
19:48 At the water park on my favourite walk, a man asked me about my recording equipment, enormously self-conscious, I answered him vaguely, and was very aware of stealing sounds, potently less invasive than image-taking.,. I also became aware of another very practical feminised aspect of soundwalking, the accessibility it perhaps affords me, to be a young woman while recoding in spaces populated by children. My voice in this section is a dim echo, an amused discomfort in composition... an access denied at night in the same park.

22:34 Stones in the wolves belly (my favourite part of the story, the one most explicitly referring to my concerns with creative swelling, and its oppositedeadening creative sterility), centralised as a reference in the middle of the soundwalk, refer to the experiments with stones throughout, attempting to make concrete objects of my ideas...

22:44 Over-layered, messily woven (like my mat), I here provide a second option for the ending of the Grimm version.

24:38 The fluttering sounds of the birds wings are like the turning pages of a book (the book absent in my fragmented narration). If these sounds also allude to flight, they represent my actual consequence to the physical encounter with the noises of certain sounds on the walk, such as the birds which fly away as I approach them, and then the indifferent sounds of the helicopter later...

24:58 I now fold-in a recording distorted by static. It is of birdsong, and there is also another of children's voices, both taken from outside my house. The environmental distortion of traffic is pronounced in my retention of this static in recording, to listen to this section is discomforting. By using recording of distant children's voices, I acknowledge Schafer's concern that children do not listen acutely... Krause's niche hypothesis and the evocation of birdsong as emblematic of a healthy listening 
environment, has encouraged me to listen, for example, for a give-and -take amongst children's voices.

As mentioned earlier, I have long been fascinated by birds and birdsong as a forum for exploring 'nature' as both refined and bestial. The skilled listening of the soundscaping educational procedures should enable us to take solace from the placing, meditative, natural sounds of birds. There is certainly proof that this is a healthy, healthful activity: But upon translation, though artistic projects such as Hitchcock's 'The Birds', and poets such as Baudelaire, birds are ascribed horrific attributes, harpies and close cousins to the dinosaur, ultimate symbols of extinction and human absence. Children, too, share this nature/culture ambivalence...

27:04 Reintroduction of the most familiar part of the tale, again imposing a narrative over the give-and-take of the children playing and the birds singing...

30:04 Return to the soundwalk recording...

My use of helicopter and aeroplane sounds evoke the awesome immediacy of sound which is travelling from an objects so visually distant.

34:03 The Dahl version of Little Red Cap from 'Dirty Beasts': This poetic version is a wittily translated story, wherein Little Red Cap dons not only a feminine cloak of red, but the masculine bestial fur-coat of the wolf! A fanciful inclusion, it also draws emphasis upon the gendered nature of composition to which I have referred throughout. It is also contrasted to the first reading, this rhymed version is conducive to oral recitation.

37:45 Bicycle sounds, which I continually tried to capture as locomotive devices, were very difficult to catch! 
38:59 The boiling sounds are again introduced, this time with the studio-recorded stone noises played at $15: 57$

42:28 The foot-step, pedal mike recording is again sounded, as an exit from the recording.

\section{The Mat:}

The mat which accompanies my audio project is a complementary object, and so the theoretical attention it merits should be tempered with an understanding that any associations it gleans are very playful, personalised, and intellectually amateur. Nonetheless, they are dignified by what I believe is a real power and profundity afforded to the art (and craft) of embroidery, as process and product, and these are potently woven into the fabric of both this essay and the audio piece. Thus, to undertake a serious literature review of embroidery and art history, its sociological and political connotations, would be illuminating, and my research towards this end has been entirely compelling. However, to claim such a context for myself, with any magnitude, seems fraudulent. As I have made stated, the mat was an entirely spontaneous offshoot of the audio and essay-writing process, and so I present in this section a foray into its relevance which I consider essential if partial. I am sure this section depicts the mat in form: a terse, manic composition.

The domestication of my studio experience, a parallel process to the actual composition, corresponds to what I have deemed the parallel audience for my project: not only an academic reception, but also that of my young sisters. The maternal thread of my paper incites (personally) a recall of my admittedly compulsive behaviours surrounding sewing. A previous embroidered project, (a tent with surround-sound 
speakers), after being displayed in class, was immediately mailed to my mother in the England, an amusingly obvious life for the work beyond its first showing!

Sewing and embroidery in feminist theory and art history offer a means to explore divisions between domestic and public, craft and art, masculine and feminine. Undoubtedly, the sewing exercise for me is a further statement of adopting a feminine mode, and in this sense I conform to the Victorian notions of embroidery as a naturally feminised practice (Parker 1986, Parker and Pollock 1981).

The roughness of my tapestry, which I have many times considered correcting, is an inscription of time and personality, two acts fundamentally in synch with the imposition of narrative over the soundscape piece. The American Heritage Dictionary says 'to embroider' is not only to 'ornament (fabric) with needlework', but also to 'embellish (a narrative, for example) with fictitious detail or exaggerations.' Benjamin employs the image of the female embroiderer to explore the essentially artisanal nature of storytelling (1955: 107-8). Metaphorical parallels between writing and weaving abound, writing as a craft reworked a carefully placed, a learned activity which is depicted.

My concern with the oppositional/ conflictual generation of imagination in creative practice, as well as my attraction to Cage's and soundscaper's ideas about the potentially meditative capacities of soundscape, evokes Freud's hypothesis that hysteria originates in daydreams 'to which needlework and similar occupations render women especially prone' (cited in Durham 1990: 345): this most domestic of acts is apt to lead to massively unhinged subversion and individuation! Hunter comments on 
this hypothesis by stating that '...people left to embroidery are bound to embroider fantasies' (1985: 94 in Durham 1990: 345). In my particular case, whilst the mat represents a concern with imagination in the project, it is also an act of induced calm. I needed to sew in order to string together, to make material, some of my experiences ('sewing' is definitionally a joining, a repeated fixing). After composing the soundscape, I was literally dis-placed, living in other people's houses for two months, brittle and anxiously avoiding home and the soundscape thereof.

Hunched and immobilised in the act of sewing, I was isolated from the mobility which my soundscape demands. I was sewing up the belly of the wolf, sewing up and containing my messy self, messy imagination and exposed concerns with integrity and fertility. The self-containment of this process (Parker 1986: 11), is linked to what I have posited as the self containment of the of female anatomy, so dangerously open and receptive, as we are to sound, and to unwanted pregnancy, and yet the simultaneously stasis which is the extremity of chthonian liquid nature (Paglia 1992: $108-9$ ), in pregnancy ${ }^{19}$. In this vein, I am subject to the criticism of feminist theorists who suggest that artistic needlework should oppose or subvert connections of 'women's identity as being defined through their bodies, and sexuality as an essential basis for a female aesthetic' (Jeffries 2001: 190) in this particular project.

The fact that the mat will be trampled, used, and altered, posits it at the intersection of gentile decorative embroidery, and functional sewing, darning, and constructive needlecraft. The trodden mat can represent participation, activation and

\footnotetext{
${ }^{19}$ Parker discusses how embroidery can be characterised as both narcissistic and vain, as solitary female activity, and also as self-less maternal giving, in the production of clothes and piece-work (1986: 14).
} 
destruction...there is certainly something of the salvage mode identified with both soundscaping and ethnography in the rapid stitching of scraps of fabric ${ }^{20}$.

Similarly, as a response to the technologies compositional practice (Schapiro in Jeffries 2001: $189^{21}$ ), and that of writing (Jeffries 2001:191), it offers a further exploration of what it means to give voice to inscribe persona: Embroidery as a mechanical act, connoted with reproducibility, is challenged in concertedly artistic endeavours, and re-evaluations of the significance of embroidery in biography. As a way of knowing, we must look to all forms of expressiveness. Examining the way that people craft allows a density of understanding which is akin to 'giving voice' to unconventional speaking in anthropological and acoustic ecological practices ${ }^{22}$. The cacophony of representation this might suggest, however, given my intent to focus upon audio, does not undermine my principle focus upon the latter, as the mat is a playful means to listen, and not in itself a project.

The sewing of the nuendo imagery as an evocation of feminised, domestic craft, an act I undertook in a home, is obviously a statement of antagonism toward the technological apparatus required to compete my project and this is felt; but at the same time it is an adulation of the (to me) mysterious capacities of compositional apparatus: it is an ode. The importance of parallel texts is social science is

\footnotetext{
${ }^{20}$ I should mention that part of my nervousness at claiming weighty theoretical grounds for my embroidery are derived from a recognition that such claims would require serious anthropological research

${ }^{21}$ Of Schapiro, a working artist, Jeffries writes 'The realisation that bits and pieces of fabric could close the gap between pure studio and the everyday reality of her home, allowed Schapiro to sat that, "the story of my evolution is typical of what happens when fabrics become a metaphor for a quiet revolution.' (Jeffries 2001: 192)

22 In Metamorphoses, Philomela's tongue is cut out by her brother, in order that she cannot tell her sister that he has raped her; Seeking an altemate means of communication, she composes, on a loom, a depiction of her wrongs, and a servant carries this to Procne. Again, an altemate vocalisation is explored, in this instance very literal: voicing is active, creative, and subversive.
} 
quintessentially the recognition that the only 'answer' to a tapestry, a soundscape, a story, is another tapestry, soundscape, or story. In sewing this mat I attempt to add depth to an understanding of process in my work, the mat therefore speaks as an invitation for listenership and as an evocation of the process of recording. The apparent absence of subjectivity in embroidery, identified by $\operatorname{Parker}^{23}$ requires the listener, the walker, to recognise or ignore (if they choose) the subject of the piece (myself) ${ }^{24}$. The comic notion that the mat represents a context of some sort should be juxtaposed with my desire that the ideal sounding space for the composition is in fact within its original soundscape, as I have stated, I listen to it mostly within the place in which it was recorded, in my neighbourhood ${ }^{25}$. The mat is not landscape, it is not a place, it is an invitation and a reference ${ }^{26}$.

I hinted, in the beginning of this section, at the vast array of meaning which can be derived from embroidery - monastic sewing in the middle ages, the gentile activities of a good woman, the current concern with clothing as evocative of sweat-shops destroying the eyes of children in developing nations. Evidently, the Victorian link I have referred to conceals a complexity of social, economic, and political factors which connected women and embroidery since the Middle Ages (Parker 189: 1986).

\footnotetext{
23 'embroiders employed the needle, not the pen - they left no records of their attitudes toward their subject matter.' (1986: 102)

${ }^{24}$ Similarly, 1 would characterise my soundscape as ambient insofar as 'Ambient music must be able to accommodate many levels of listening attention without enforcing one in particular: it must be as ignorable as it is interesting.' (Eno cited in Toop 1995:9). This is not to say that it is a kind of Musak, the archenemy of soundscapers (often called Moosak in the literature, explored by Westerkamp 1984) ${ }^{25}$ Westerkamp encouraged that soundwalks be taken within ones own neighbourhood in order that the exploration of attention to unheard sounds and thus the prominence of self-placement in accordance with neglect, be emphasised (1997:10). This also seems to speak to Schafer's concern in pieces such as 'Music for Wilderness Lake' that the environment/ soundscape space for music be part of the composition and performance event

${ }^{26}$ It is also a reference to composition, to motion: Casey (1996 cited in McCartney 23004, pages unnumbered) writes that bodies in place are bodies in motion, a remark 1 realise 1 employ with almost comic literalism!
} 
My contention that needlework and femininity are intricately connected is better explored by other theorist, such as Parker, and I have tried to highlight how sewing in this project was less an act of feminist subversion, than one of personal expression. At the same time I will state that, rather than a Victorian 'Angel in the House', this piece is presented as meant for imposed signatures, for muddy dirty feet. It is a customised piece, thus involving personality in a way that has become crucial for understanding twentieth century art practices, and certainly I can claim no real life for this piece (unlike my audio piece and its ripples) beyond its aesthetic presentation. 


\section{8: BIBLIOGRAPHY:}

Abu-Lughod, L. 1989 'Bedouins, cassettes, and technologies of public culture.' In Middle East Report 159: 7-11

Adams, S. 1983 R. Murray Schafer Toronto: University of Toronto Press

Amer, G and Erving, S. 2004 'Looking Both Ways' PEM visited in 2004 at http://www.pem.org/lbw/pair amer.html.

Anderson, B. 1991 Imagined Communities London: Verso

Appadurai, A. 1991 'Global Ethnoscapes: notes and queries for a transnational anthropology' in RG Fox (ed) Recapturing Anthropology Sante Fe, NM: School of American Research Press

Astuti, R. 2001 'Are we all Natural Dualists? A Cognitive Developmental Approach' Journal of the Royal Anthropological Institute 7: 429-447.

1998 “'It's a boy!' 'It's a girl!' Reflections on sex and gender in Madagascar and beyond,' in M. Lameck and A Strathern (eds) Bodies and Persons. Comparative Perspectives from Africa and Melanesia. Cambridge, Cambridge University Press.

Beck, A. 2004 'Listening to radio plays: fictional soundscapes' visited at http://www.interact.uoregon.edu/MediaLit'wfae/readings/Listentoradio.html

Beck, G. 1993 Sonic Theology: Hinduism and Sacred Sound. Columbia, S.C. South Carolina Pres.

Benjamin, W. 1955 'The Storyteller' in Illuminations. New York: Harcourt, Brace and World.

---- 2001 "The Work of Art in the Age of Mechanical Reporducibility." In Durham and Kellner (eds) Media and Cultural Studies: Keyworks Oxford: Blackwell Publishing.

Berleant, A. 1985 'Toward a Phenomenological Aesthetics of Environment.' Pp 112 28 in D Thde and H Silverman (eds) Descriptions. Albany: State University of New York Press.

Bloch, M. and Guggenheim, S. 1981 "Compadrazgo, Baptism and the Symbolism of a Second Birth." N.S, Mam, vol. 16.

Boddy, J. 1988 'Spirits and Spouses: possession as a system of Communication among the Malagasy speakers of Mayotte' in American Ethnologist 7 (4): 318-332.

Bohme, G. 2000 'Acoustic Atmospheres: A Contribution to the Study of Ecological Aesthetics.' In Soundscape: The Journal of Acoustic Ecology 2000 1/1 pp 14-18. 
Beauvoir, S. de [1949] 1997 The Second Sex transl. H.M. Parshley London, Vintage.

Bronzaft, A. 2000 'Acoustic Ecologists and Environmental Psychologists: Working Toward a Quieter and Healthier Soundscape.' In Soundscape 1 (2):24-6

Carpenter, E. 1972 Oh, What a Blow That Phantom Gave Me! Toronto: Bantam Books.

Carsten, J. 1995 'The substance of kinship and the heat of the hearth: feeding, personhood and relatedness among Malays in Paulau Langkawi.' American Ethnologist, vol 22, no 2, pp223-241.

Carter, K. 1993 'The place of story in the study of teaching and teacher education' Educational Researcher $22 \mathrm{pp} 5-12$.

Clark, K. 1956 The Nude: A Study in Ideal Form Princeton: Princeton University Press.

Clifford, J. 1988 The Predicament of culture: twentieth-century ethnography, literature and art. Cambridge, MA: Harvard University Press.

Clifford, J. and Marcus, E. (eds) 1986 Writing Culture London: University of California Press.

Coles, R. 1989 The call of stories: Teaching and the moral imagination. Boston, Houghton Mifflin.

Connor, S. 2004 'Ears Have Walls: On Hearing Art: S Connor, talk for 'Bodily Knowledges: Challenging Occularcentricity.' At the Tate Modern, Februaru 2003. visited at http://www.bbk.ac.uk/eh/skc/earshavewalls/

Conquergood, D. 1991 'Rethinking Ethnography: towards a critical cultural politics.' Communication Monographs 56 (June): 179-94

Comaroff, J\&J. 1992 Ethnography and the Historical Imagination. Boulder, Westview Press.

Debord, G. [1958] 1981 'Theory of The Dérive', Internationale Situationniste \#2', in K Knabb (ed), Situationist International anthology, Berkeley: Bureau of Public Secrets.

Dietze, L. 2000 'Learning is Living: A voustic Ecology as Pegagoical Ground A Report on Experience.' In Soundscape: Journal of Acoustic Ecology 2000 1/1 pp3023.

Douglas, M. 1975 Implicit Meanings London, Routledge and Kegan Paul.

Douglas, M. 1966 Purity and Danger. London, Routledge 
Drever, J L. 2002 'Soundscape Composition: the convergence of ethnography and acousmatic music.' In Organized Sound 7 (1): 21-27.

Duffy, D. 1969 Marshall McLuhan Toronto: McClelland and Stewart Ltd.

Durkheim, E. and Mauss, M. 1963 Primitive Classification. Cohen and West, London.

Durham, C. 1990 'The Subversive Stitch: female craft, culture, and ecriture.' In Women's Studies 17: 341-359.

Eade, J. (ed) 1997 Living the Global City: Globalisation as Local Process. New York, Routledge.

Feld, S. 1994 'From Ethnomusicology to echo-muse-ecology: Reading R Murray Schafer in the Papua New Guinea Rainforest. In The Soundscape Newsletter 8 (June)

--- 1982 Sound and Sentiment: Birds, Weeping, Poetics and Song in Kaluli Expression. Philadelphia: University of Pennsylvania Press.

Franklin, U. 2000 'Silence and the Notion of the Commons.' In Soundscape: The Journal of Acoustic Ecology 2000 1/2 pp14-17.

Gell, A. 1995 'The Language of the Forest: Landscape and Phonological Iconism in Umeda' In E Hirsch and M O'Hanlon (eds) The Anthropology of Landscape. Oxford: Oxford University press.

Gille, Z. and O'Riain, S. 2002 'Global Ethnography' in Annual Review of Sociology 28:271-95

Goldschmidt, W. 1993 'On the relationship between biology and anthropology' in Journal of the Royal Anthropological Institute (28): 341-359

Greenlaugh, S. 1995 'Introduction' in Situating Fertility: Anthropological and Demographic Enquiry. Cambridge, Cambridge University Press.

Hannerez, U. 1989 'Notes on the Global Ecumene'. In Public Culture 1(2):66-75

Howes, D. (ed) 1991 The Varieties of Sensory Experience Toronto, University of Toronto Press.

Inda, J. X. and Rosaldo, R. 2002 'Introduction' in Inda, J and Rosaldo, R eds The anthropology of globalisation: a reader. Oxford, Blackwell 65-80.

Jay, M. 1994 Downcast Eyes: The Denigration of Vision in twentieth-century French Thought California: University of California Press.

Jeffries, J. 2001 'Textiles' in (eds) F Carson and C Pajaczkowska Feminist Visual Culture. New York: Routledge. 
Karlsson, H. 2000 'The Acoustic Environment as a Public Domain.' In Soundscape: The Journal of Acoustic Ecology $20001 / 2$ pp 10-13.

Kearney, M. 1995 'The Local and the Global: The Anthropology of Globalisation and Transnationalism' in Annual Review of Anthropology 24:547-65

Kolber, D. 2002 'Hildegard Westerkamp's Kit's Beach Soundwalk: shifting perspectives in real world music' in Organised Sound 7 (1) 41-3

Krause, B. L. 1993 'The niche hypothesis: A hidden symphony of animals sounds, the origins of musical expression and the health of habitats.' Explorers Journal $71 / 4 \mathrm{pp}$ 156-60.

Kristeva, J. 1987 'Stabat Mater’ from Tales of Love (Transl. L.S. Roudiez) New York: Columbia University Press.

Leach, E. 1966 'Virgin Birth' Proceedings of the Royal Anthropological Institute for 1966, 39-49.

Levi-Strauss, C. 1963 Totemism. Beacon Press, New York.

Lewis, I. 1989 Ecstatic Religion. Routledge, London.

Malinowski, B. 1922 Argonauts of the Western Pacific. An Account of Native Enterprise and Adventure in the Archipelagos of Melanesian New Guinea. London: Routledge and Kegan Paul.

Marcus, G. E. 1995 'Ethnography In/Of the World System: the Emergence of Mutlisited Ethnography'. In: Annual Review of Anthropology 24 :95-117

Marcus, G. E. and Fischer, M. M. J. 1986 Anthropology as Cultural Critique: A Experimental Moment in the Human Sciences. London: University of Chicago Press.

Martin, S. A. 2004 'I Voice, therefore I know I Am.' In The Arts in Psychotherapy 23 (3): 261-8.

McCartney, A. 2004 'Sounding Places with Hildegard Westerkamp.' PhD Dissertation submitted to York University Graduate Programme in Music. Visited at http:/www.emf.org/artists/mccartney00/text.html

McCartney, A. 2000 'Soundwalking Blue Montreal' in Soundscape: Journal of Acoustic Ecology 1 (2): 28-9

McLuhan, M. and Carpenter, E. 1960 'Acoustic Space' in E Carpenter (ed) Explorations in Communication. Boston: Beacon Press.

McLuhan, M. 1967 The Medium Is the Massage: An Inventory of Effects, with Quentin Fiore. New York: Bantam. 
---- 1964 Understanding Media: The Extensions of Man. New York: McGraw Hill, 1964; London: Routledge.

Miller, W. [1986] 2004 'Silence in the Contemporary Soundscape' Thesis for UNC 1986. Visited at http://interact.uoregon.edu/MediaLit/WFAE/readings/Thesis.pdf

Mulvey, L. 1989 Visual and Other Pleasures Bloomington: Indiana University Press.

Murch, W. 1994 'Forward' in M. Chion Audio-Vision: Sound on Screen. New York: Columbia University Press.

Norman, K. 1996 'Real-World Music as Composed Listening' in Contemporary Music Review 15:1 pp 1-27.

Ong, W. 1982 Orality and Literacy New York: Methuen.

Ortner, S. 1974 'Is Female to Male as Nature is to Culture.' In Woman, culture and society L. Lamphere and M. Z. Rosaldo (eds) Stanford: Stanford University Press.

Paglia, C. 1992 'Sexual Persona: The Cancelled Preface' in Sex, Art and American Culture. New York: Vintage Books.

--- 1990 Sexual Personae New York: Vintage.

Parker, R. 1986 The Subversive Stitch: Embroidery and the Making of the Feminine. London: The Women's Press.

Parker, R. and Pollock, G. 1981 'Crafty Women and the Hierarchy of Art' in Old Mistresses: Women, Art and Ideology London: Routledge and Kegan Paul.

Savigliano, M. 1995 Tango and the Political Economy of Passion. Boulder, CO: Westview.

Seeger, A. 1975 'The Meaning of Body Ornaments' Ethnology 14 (3): 211-24

Schafer, R. M. 2004 'The Glazed Soundscape', from The Soundscape Newsletter, number 4, September, 1992. visited at http://interact.uoregon.edu/MediaLit/WFAE/studies/

--- 1992 A Sound Education. Indian River: Arcana Editions

---- 1985 'McLuhan and Acoustic Space' in The Antigonish Review LXII pp 105113.

--- 1977a The Turning of the World New York, Knopf.

---- 1977b European Sound Diary Burnaby, ARC Publications.

-.-- 1977c (ed) Five Village Soundscapes Bumaby, ARC Publications. 
---- $1977 \mathrm{~d}$ Music in the Cold Bancroft, Arcana.

---- 1967 Ear Cleaning. Toronto: Berandol.

Stoller, P. 1984 'Sound in Songhay Cultural Experience.' American Ethnologist 11 (3) $559-70$

Synnott, A. 1991 'Puzzling over the Senses: From Plato to Marx.' From Howes, D (ed) The Varieties of Sensory Experience Toronto, University of Toronto Press.

Theissen, I. 1999 'The essence of being: procreation and sexuality in mid-century Macedonia' 177-201 In Loizos, $P$ and Heady, $P$ (eds) Conceiving persons : ethnographies of procreation, fertility, and growth. London, Athlone Press.

Toop, D. 1995 Oceans of Sound London: Serpent's Tail.

Truax, B. 2004 'Soundscape Composition as Global Music' Conference text for Sound Escape, Trent University, July 1, 2000. Visited at http://www.sfu.ca/ truax/soundscape.html

---- 2002 'Genres and Techniques of Soundscape Composition as Developed at Simon Frazer University.' In Organised Sound 7 (1) pp 5-14.

---- 1996 'Soundscape, Acoustic Communication and Environmental Sound Composition.' In Contemporary Music Review 15:1 47-63.

1984 Acoustic Communication New Jersey: Ablex Publishing.

Tsing, A. 2000 'The Global Situation' in Cultural Anthropology 15 (3):327-360

Tuzin, D. 'Miraculous Voices: The Auditory Experience of Numinous Objects' in Current Anthropology 25 (5): 579-596

Tyler, S. 1984 'The Vision Quest in the West of What the Mind's Eye Sees.' Journal of Anthropological Research 40: 23-40

Weiner J. F. 1991 The Empty Place: Poetry, Space, and Being among the Foi of Papua New Guinea. Bloomington: Indiana University Press

Westerkamp, H. 2004a Soundwalking http://membres.lycos.fr/ musicand/BASIC/ECOLOGY/WFAE.htm.

2004b Interviews Index,

http://www.media.hyperreal.org/zines/est/intervs/westerk.htm

--- 2004c 'Soundscape Composition: Linking Inner and Outer Worlds' written for Soundscape before 2000 Amsterdam, November 19-26, 1999, visited @ From http://members.lycos.fr/musicand/BASIC/ECOLOGY/WFAE.htm 
---- 1998 Gently Penetrating Beneath the Sounding Surfaces of Another Place in Harangue II. CD. Vancouver, earsay.

---- 1997 'Soundwalking from Home' in The New Soundscape Newsletter May: 10

---- 1988 'Listening and Soundmaking: A study in Music-as-Environment.'

MA Thesis, Simon Frazer University

---- 1987 Cricket Voice For two-channel tape. Premier: June 1987, Community Arts Council, Vancouver.

---- 1984 Cool Drool. For Spoken voice and two-channel tape. Premier: February 1984, Vancouver East Cultural Centre, Hildegard Westerkamp, voice.

---- 1974 'Soundwalking' in Sound Heritage 3 (4): 18-27

Wilden, A. 1987 The Rules are No Game London; Routledge and Kegan Paul.

Wilk, R. 1995 'Leaming to be Local in Belize: global systems of common difference.' In D Miller (ed) Worlds Apart London, Routledge.

Wischart, T. 1986 'Sound Symbols and Landscapes' In S Emmerson (ed) The Language of Electrocoustic Music. London: Macmillan.

Wrightson, K. 2000 'An Introduction to Acoustic Ecology' in Soundscape: The Journal of Acoustic Ecology 2000 1/1 pp 10-13.

Bibliography for Soundscape:

All versions used in this recording can be found in: Orenstein, C. 2002 Little Red Riding Hood Uncloaked New York, Basic Books, with the exception of 'Ladle Rat Rotten Hut', which is written by H.L. Chace and is Published in the Whole Earth Catalogue, 1980.

Recordings are taken from the Trinity Bellwood's Park area of the Garrison Creek trail. 